\title{
Steric Interactions Influence on Electron Transfer Efficiency in Meso-Nitrophenylporphyrins and their Chemical Dimers
}

\author{
EDUARD I. ZENKEVICH, EVGENII I. SAGUN, VALERII \\ N. KNYUKSHTO, ALEXANDER M. SHULGA, DMITRY \\ A. STARUKHIN and SERGEI M. BACHILO \\ Institute of Molecular and Atomic Physics, Natl. Acad. Sci. of Belarus, \\ 220072 Minsk, Belarus
}

\begin{abstract}
Steric interactions upon mono- and di-meso-phenyl substitution in octaethylporphyrins (OEP) and their chemical dimers with the phenyl spacer manifests itself in the dramatical $\mathrm{T}_{1}$-state lifetimes shortening at $293 \mathrm{~K}$ (from $\mathrm{ms}$ down to $\mu \mathrm{s}$ in degassed toluene solutions) without any influence on spectral-kinetic parameters of $S_{0^{-}}$and $S_{1}$-states. This effect is explained by non-planar dynamic conformations in excited $\mathrm{T}_{1}$-states caused by the phenyl ring torsional librations around a single $\mathrm{C}-\mathrm{C}$ bond. For meso-ortho-nitrophenyl substituted OEPs the $S_{1}$-state quenching is caused by the direct "through space" electron transfer to low-lying $\mathrm{CT}$ state while for the corresponding Pd-complexes the direct electron transfer takes place from the locally excited $\mathrm{T}_{1}$-state. For the last two cases steric interactions provide the optimal geometry with high electronic coupling between porphyrin macrocycle and nitro-group.
\end{abstract}

Keywords: porphyrins; steric interactions; electron-accepting $\mathrm{NO}_{2}$-groups; $\mathrm{S}_{1}$ - and $\mathrm{T}_{1}$-state quenching; conformational dynamics; electron transfer

\section{INTRODUCTION}

According to nowadays conception the conformational distortion 
differences of tetrapyrrole pigments lead to significant changes of electronic properties of these chromophores, and correspondingly may play a decisive role in controlling photochemical events in photosynthetic antenna and reaction centre protein complexes. In addition, synthetic porphyrins and their dimers, covalently linked to various electron acceptors are widely used to model some aspects of photoinduced electron transfer (PET) events ${ }^{[1]}$. In some cases, donoracceptor pair contains an inserted phenyl ring as a spacer, and PET pathways ("through bond" or "through space") depend essentially on electronic properties of the spacer ${ }^{[2]}$. At the same time, specific steric interactions of meso-phenyls with bulky substituents in sterically encumbered porphyrins manifest themselves in non-planar deformations of tetrapyrrole ring accompanied by the essential increase of the nonradiative deactivation of porphyrin excited electronic states ${ }^{[3]}$ and influence on PET efficiency ${ }^{[4 !}$. Recently, we found that in mono- and di-meso-phenyl substituted octaethylporphyrins, OEP steric interactions of substituents lead to the unusual $T_{1}$-state lifetime shortening in liquid solutions at $293 \mathrm{~K}^{[5]}$. Here we analyse the role of conformational dynamics and steric hindrance effects in the efficiency of PET for octaethylporphyrins with meso-nitrophenyl substitution.

The main experimental results have been obtained in solvents of various polarity at $77-300 \mathrm{~K}$ using laser transient absorption measurements ( $\left.\lambda_{c x}=532 \mathrm{~nm} . \Delta t_{1 / 2}=25 \quad \mathrm{~ns}\right)$, fluorescence and phosphorescence data. 


\section{EXPERIMENTAL RESULTS AND DISCUSSION}

Steric interactions in mono- and di-meso-phenyl substituted OEP type molecules (free bases, $\mathrm{Zn}$ - and Pd-complexes, Figure 1) and their chemical dimers with the phenyl spacer manifest themselves in the strong shortening of triplet lifetimes (by 300-1000 times) and the decrease of phosphorescence quantum yields (by 250-350 times for Pdcomplexes) in degassed toluene solutions at $293 \mathrm{~K}$ without any influence on spectral-kinetic parameters of $S_{0}$ and $S_{1}$ states. This specific quenching is not observed in the following cases: 1) the meso-phenyl absence;

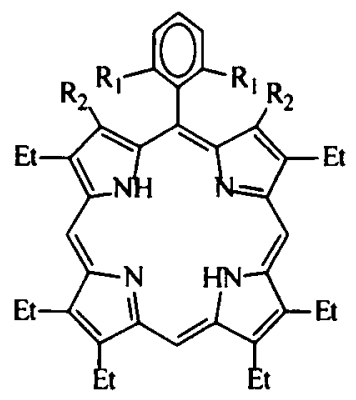

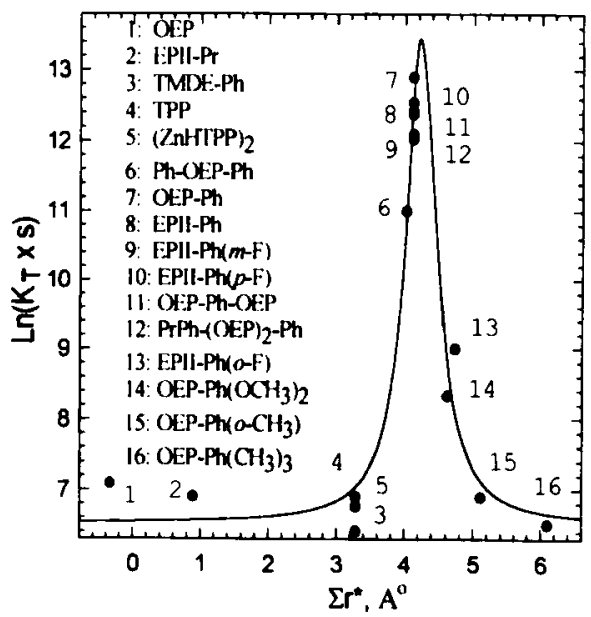

FIGURE 1. The basic structure of meso-phenyl substituted OEPtype molecule (left) and the experimental correlative dependence of $T_{1}$-state deactivation rate constants $k_{T}$ on the overlap geometrical parameter $\Sigma \mathbf{r}^{*}$ (right), $\ln \left(k_{\mathrm{T}}\right)=\ln \left(1 / \tau_{\mathrm{T}}\right)=\mathrm{f}\left(\Sigma \mathbf{r}^{*}\right)$, for the compounds with various $R_{1}$ and $R_{2}$ substituents (toluene, 293 K). 
2) the absence of bulky $\beta$-pyrrole substituents, $R_{1}=H ; 3$ ) the simultaneous existence of bulky substituents $\mathrm{R}_{1}\left(\mathrm{OCH}_{3}, \mathrm{CH}_{3}, \mathrm{~F}\right)$ and $\left.\mathrm{R}_{2}\left(\mathrm{C}_{2} \mathrm{H}_{5}\right) ; 4\right)$ the use of rigid polymeric films at $295 \mathrm{~K}$ and/or glassy solvent matrixes at $77 \mathrm{~K}$. The observed effects are connected with torsional librations of the phenyl ring around a single $\mathrm{C}-\mathrm{C}$ bond in sterically encumbered porphyrins of OEP types leading to non-planar dynamic distorted conformations realised in the excited $T_{1}$ states namely. Figure 1 shows that the drastic rise of $k_{T}$ values for aryl-substituted OEPs, the dimer OEP$\mathrm{Ph}-\mathrm{OEP}$ and their $\mathrm{Zn}$-complexes is realised in a narrow range of the geometrical factor $\Sigma \mathrm{r}^{\circ}=3.8+4.5 \mathrm{~A}^{\circ}$. In the range of $\Sigma \mathrm{r}^{\circ}<3.4 \mathrm{~A}^{\circ}$ librations of the meso-phenyl around C-C bond do not cause the essential non-planar distortions of the porphyrin plane, while at

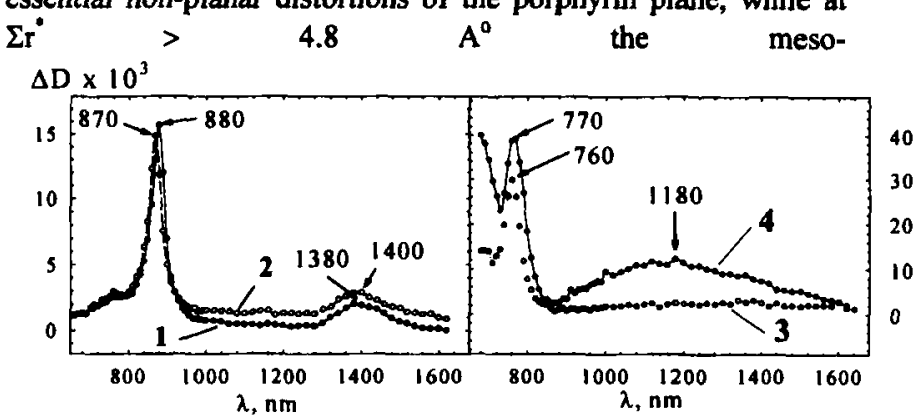

FIGURE 2. Transient absorption spectra (optical densities $\triangle D$ ) following a $25 \mathrm{~ns}$ laser flash excitation of PdOEP-Ph $\left(0-\mathrm{NO}_{2}\right)$ in toluene (1) and acetone (2), PdOEP (3) and PdOEP-Ph (4) in toluene (degassed solutions, $293 \mathrm{~K}, \lambda_{\text {exc }}=532 \mathrm{~nm}$ ).

phenyl librations are essentially limited within $T_{1}$-state lifetimes (like in rigid systems or at $77 \mathrm{~K}$ ) due to the steric interactions of meso- $\left(R_{l}\right)$ and $\boldsymbol{\beta}$-substituents $\left(R_{2}\right)$. A progressive distortion from the porphyrin macrocycle planarity for PdOEP-mesophenyl molecule manifests itself in the formation of a wide non-structural band $\left(\lambda_{\max }=1180 \mathrm{~nm}\right)$ in transient $\mathrm{T}-\mathrm{T}$ absorption spectrum, while for a planar Pd-OEP molecule such band is absent. 
For meso-ortho-nitrophenyl substituted OEPs (free bases) the effective fluorescence quenching $\left(\varphi_{\mathrm{F}}=0.002 \div 0.005, \tau_{\mathrm{s}} \approx 0.1 \mathrm{~ns}\right.$ in toluene at $293 \mathrm{~K}$ ) is observed, being stronger upon addition of the second phenyl ring with ortho- $\mathrm{NO}_{2}$-group and the solvent polarity rise. In this case, it was shown that steric hindrance interactions at the "apparent " geometrical overlap of $\Sigma r^{*}>4.8 \mathrm{~A}^{\circ}$ provide the optimal geometry with high electronic coupling between porphyrin macrocycle and nitrogroup. As a result, the observed quenching of locally excited porphyrin $\mathrm{S}_{1}$-state is due to the effective direct "through space" PET (the rate constant $\mathrm{k}_{\mathrm{el}}^{\mathrm{S}}=9.5 . \times 10^{9} \mathrm{~s}^{-1}$ in toluene and $\mathrm{k}_{\mathrm{et}}^{\mathrm{S}} \approx 2 \times 10^{11} \mathrm{~s}^{-1}$ in dimethylformamide, $\mathrm{DMF})$ to a low-lying charge-transfer state $\left(\mathrm{E}_{\mathrm{CT}}=1.8 \mathrm{eV}\right.$ in $\left.\mathrm{DMF}\right)$. According to Marcus formula ${ }^{|6|}$

$$
k_{e l}^{S}=\frac{2 \pi}{\hbar} \cdot \frac{V^{2}}{\left(4 \pi \lambda k_{B} T\right)^{1 / 2}} \cdot \exp \left(-\frac{\Delta G^{*}}{k_{B} T}\right)
$$

on the base of experimental $\mathrm{k}_{\mathrm{et}}^{\mathrm{S}}$ data and estimated values of the reorganisation energy $\lambda=0.7 \mathrm{eV}$ and Marcus Gibbs activation energy $\Delta \mathrm{G}^{*}=0.1 \mathrm{eV}$ in DMF we obtained the electronic coupling matrix element $V$ to be $\sim 190 \mathrm{~cm}^{-1}$. Thus, PET seems to be the limiting case of the non-adiabatic reaction with a possible manifestation of some adiabacity effects in strongly polar solvents. The enhanced non-radiative deactivation of the $T_{1}-$ state $\left(E_{T}=1.56 \mathrm{eV}\right)$ in this case is due to both the thermal activation of the radical ion pair upper-lying CT states and the rise of the intersystem crossing $T_{1} \sim>S_{0}$ rate constant.

For the corresponding Pd-complexes with the same steric hindrance interactions the energy relaxation pathways differ principally. Upon photoexcitation, PdOEP-Ph(o-NO $\left.\mathrm{NO}_{2}\right)$ molecules undergo to the 
locally exited $T_{1}$-state due to the high rate constant of the intersystem crossing $S_{1} \sim>T_{1}\left(r=8.3 . \times 10^{10} \mathrm{~s}^{-1}\right)$. Correspondingly, the observed phosphorescence quenching and $T_{1}$-states shortening (by $\geq 1000$ times, degassed toluene, $293 \mathrm{~K}$ ) for the last case is attributed to PET with participation of Pd-porphyrin triplet states. The apparent rate constant of this PET was measured to be $\mathrm{k}_{\mathrm{et}}^{\mathrm{T}}=1.5 \times 10^{6} \mathrm{~s}^{-1}$ in toluene and $k^{\mathrm{T}}{ }_{\mathrm{et}}=4.0 \times 10^{6} \mathrm{~s}^{-1}$ in DMF. According to our experimental phosphorescence data and estimations of the charge-transfer state energies it follows that $E_{r}=1.84 \mathrm{eV}>E_{C T}$ both in non-polar $\left(E_{C T}=1.79\right.$ $\mathrm{eV}$ in toluene) and polar $\left(\mathrm{E}_{\mathrm{CT}}=1.76 \mathrm{eV}\right.$ in DMF) solvents. The direct PET seems to be the non-adiabatic process in all solvents. Because of a small energy gap between $T_{1}$ - and low-lying CT-states the effective thermal exchange between these states may lead to the complex character of the $T_{1}$-state decay. In addition, the transient absorption spectra of Pd-complexes (see Figure 2) reflect the mixing of the states.

\section{References}

[1] M.R. Wasielewski. Chem. Rev. 92, 435 (1992).

[2] A. Osuka, S. Marumo, N. Mataga, et al. J. Amer. Chem. Soc. 118, 155 (1996).

[3] C.M. Drain, S. Gentemann. J.A. Roberts, et al. J. Amer.Chem. Soc. 120, 3781 (1998),

[4] D. Kuciauskas, P.A. Liddell, S.-C. Hung, et. al. J. Phys. Chem. B., 101 (1997) 429440.

[5] V. Knyukshto, E. Zenkevich, E. Sagun, et al. Chem. Phys. Lett. 297, 97 (1998).

[6] R.A. Marcus. Rev. Modern Phys. 65. 599 (1993). 